\title{
ON THE RELATION OF NET BALANCE, ICE FLOW, AND SURFACE LOWERING OF LEWIS GLACIER, MOUNT KENYA, EAST AFRICA, 1982-86
}

\author{
By Stefan Hastenrath \\ (Department of Meteorology, University of Wisconsin-Madison, Madison, \\ Wisconsin 53706, U.S.A.)
}

ABSTRACT. The second 4 year phase of a long-term observation program on Lewis Glacier, Mount Kenya, was completed in March 1986. As for the 1978-82 interval, netbalance results at a stake network and repeated mapping of the ice-surface topography allowed assessment of the mass economy by both "glaciological" and "geodetic" methods.

The general findings from the 1978-82 observations are confirmed: the vertical flow component is directed downward in the upper glacier, and upward in the lower glacier; surface lowering and negative net balance increase down-glacier; ice flow mitigates surface lowering by the negative net balance in the lower glacier, but enhances it in the upper glacier. However, the major difference between the 1982-86 and 1978-82 periods is the progressive slow-down of ice flow. This entails a reduction of mass redistribution, in consequence of which the surface lowering becomes increasingly dependent on the in-situ net balance. It is expected that this circumstance will simplify any inference on future glacier behavior.

\section{INTRODUCTION}

As outlined by Hoinkes (1970), the mass economy of glaciers can be determined independently from the "glaciological" and "geodetic" methods. In the "glaciological" approach, net balance is monitored at a network of stakes by taping at regular time intervals the distance from a fixed mark on the stake to the glacier surface. The "geodetic" method consists of repeated mapping of the glacier surface topography. While at each stake location the net balance may differ from the actual change in surface elevation, volume changes obtained from the two techniques should be consistent when integrated over the glacier as a whole. Concurrent application of these two techniques is highly desirable, but is not of ten realized. Our long-term and ongoing field program on Lewis Glacier, Mount Kenya (Hastenrath, 1984, p. 143-284), is designed to use both the "glaciological" and "geodetic" approaches. In particular, the monitoring of net balance at a stake network, together with repeated mapping of the ice-surface topography, allows insight into the role of the flow dynamics for the actual surface lowering in the upper and lower glacier. An earlier paper by Hastenrath (1983) discussed the findings from a combination of the two methods for the time span 1978-82. The present paper reports the results for the 1982-86 interval.

\section{OBSERVATIONS}

The observation program on Lewis Glacier through 1982 has been fully described by Hastenrath (1984, p 243-84). This included exploration of the glacier bedrock topography (Bhatt and others, 1980; Hastenrath, 1984, p. 152-69). The 1982-86 observations pertinent to the present paper are summarized here.

The network of stakes used for net-balance monitoring and determination of surface-flow velocity is shown in

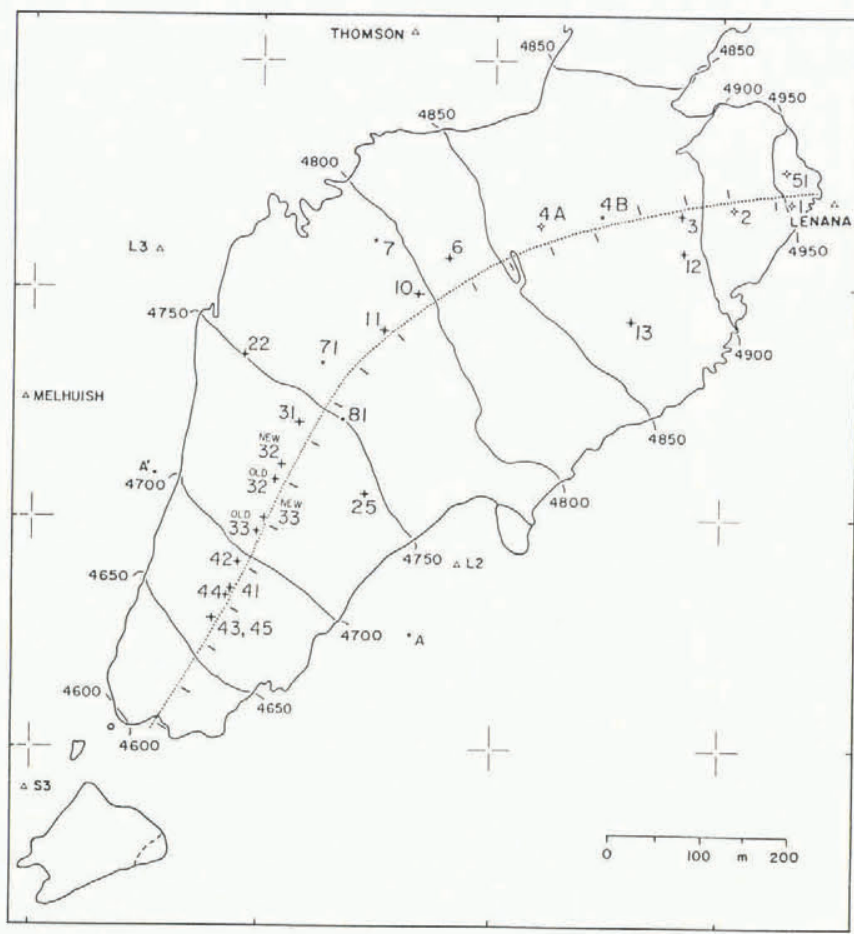

Fig. 1. Orientation map of stake network. Stations in 1982 are indicated by dots, and in 1986 by crosses. Height contours in meters are shown as solid lines. Dotted line indicates central line used as longitudinal axis of the glacier in Figure 4, with tick marks denoting $50 \mathrm{~m}$ intervals counted from the highest point of the glacier below Point Lenana.

Figure 1. Also included is the central line adopted as longitudinal axis in the longitudinal-vertical cross-section in Figure 4. Stakes in the vicinity of this central line are of primary interest in the present study. The positions of these stakes were surveyed by optical theodolite and electronic distance-measuring (EDM) equipment on 25-26 January 1982, 21-23 December 1983, 5-6 January 1985, and 1-2 January 1986. Displacement and height changes of the glacier surface with respect to a fixed mark on the stake are available over the complete 4 year interval for most but not all stations (Fig. 4). Height changes are commonly converted into liquid water-equivalent net balance, but the unconverted quantities are of interest here. Figure 2 is a contour map of height changes observed at the stake network.

Airborne mapping of the glacier-surface topography at a scale of $1: 2500$ was undertaken on 10 March 1982, 31 January 1985, and 13 March 1986 (Caukwell and 


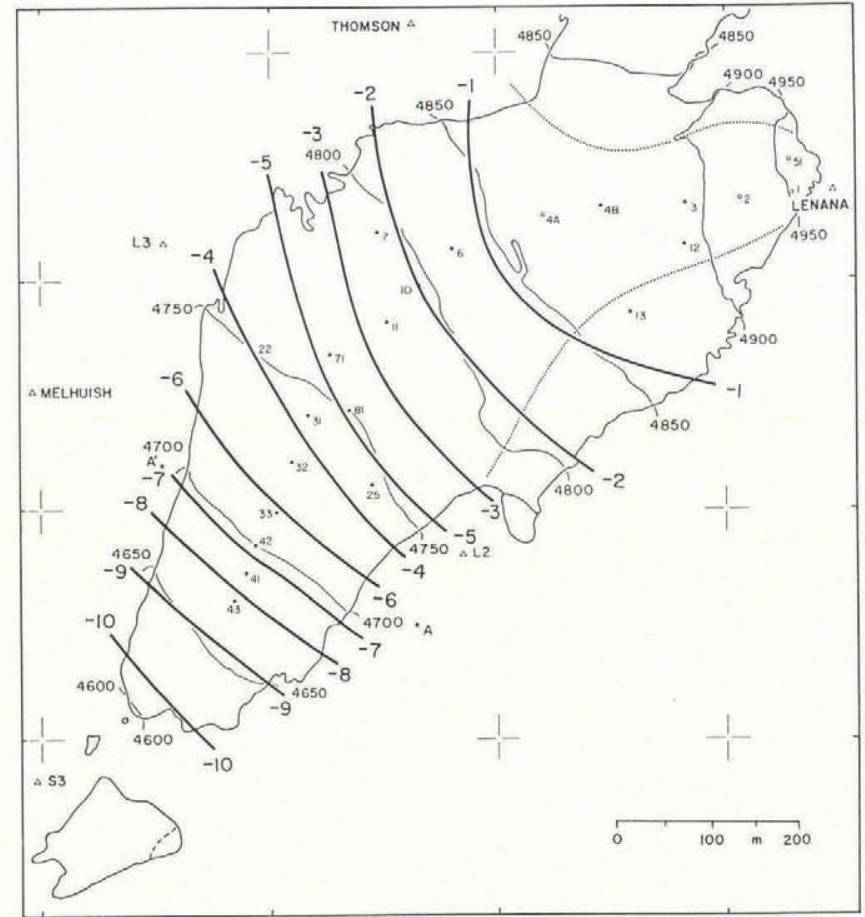

Fig. 2. Height change at stake network summed over the budget years 1982-83, 1983-84, 1984-85, 1985-86, in meters.

Hastenrath, 1982; Hastenrath and Caukwell, 1987). Graphical subtraction of the 1986 map from the 1982 map yields the chart of the observed change in ice thickness over the 4 year interval shown in Figure 3.

Error tolerances can be kept within a few centimeters for horizontal and vertical stake coordinates determined by EDM. Airborne mapping of glacier-surface topography entails uncertainties of a few tens of centimeters, but the surface elevation of the network of stakes can be obtained by EDM within a few centimeters. Tape measurements of net-balance stakes also allow determinations within a few centimeters.

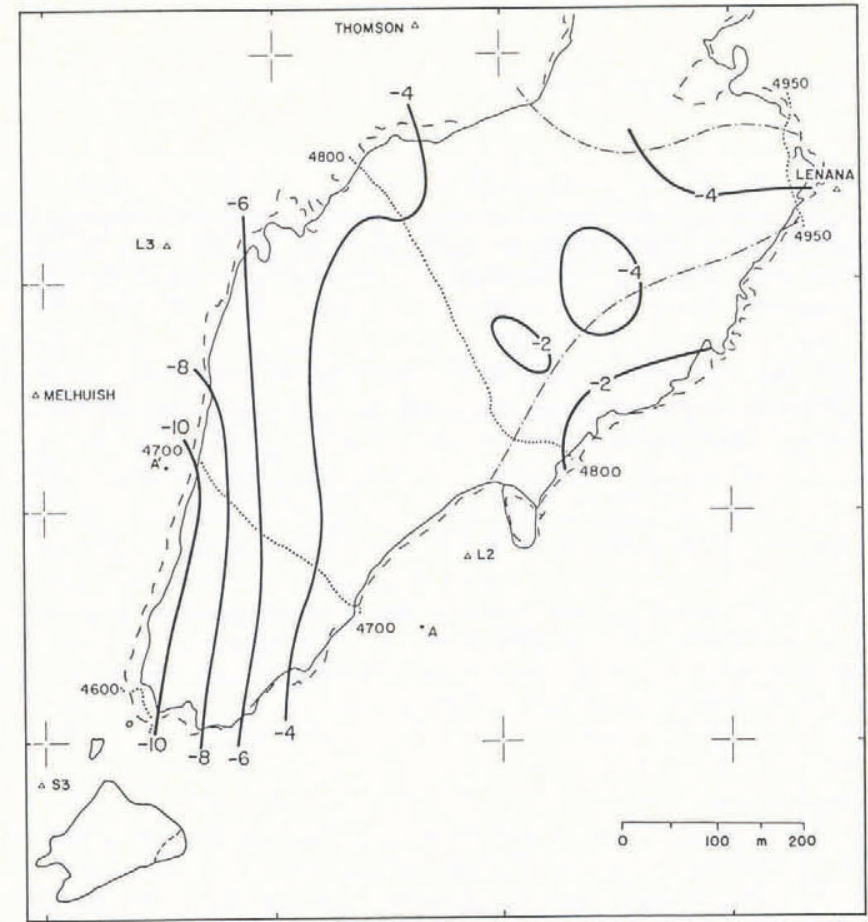

Fig. 3. Changes in ice thickness, March 1986 minus February 1982, in meters, as determined from the two sets of airborne mapping. Ice rim in 1986 is shown as a solid line, and in 1982 as a broken line. 1986 contours are shown by dotted lines.

\section{FLOW PATTERN}

Maps have been produced (Hastenrath, 1987) of the horizontal flow component at the surface of Lewis Glacier for the periods 1982-83 (25-26 January 1982 to $21-23$ December 1983), 1984 (21-23 December 1983 to 5-6 January 1985), and 1985 (5-6 January 1985 to $1-2$ January 1986). These indicate that the line chosen as longitudinal axis (Fig. 1) represents reasonably well the central flow line. As in the report of the 1978-82 results (Hastenrath, 1983), both the horizontal and vertical flow components are considered here, but they are limited to the central line (Fig. 1), so that conditions are presented in the longitudinalvertical plane.

The evaluation of horizontal and vertical flow components (in an absolute coordinate system) from the surveyed foot-points of stakes, net-balance readings (with reference to a mark on the stake), and measured changes in ice-surface topography, follows the procedure described by Hastenrath (1983). Let $\Delta z$ and $\Delta s$ denote the displacement of the stake mark in the vertical and horizontal directions, respectively, along the central line (Figs 1 and 4), during the time interval $\Delta t$, with $\tan \alpha$ the surface slope. Then the vertical component of surface flow counted positive downward is

$$
v=\frac{1}{\Delta t}(\Delta z-\Delta s \tan \alpha)
$$

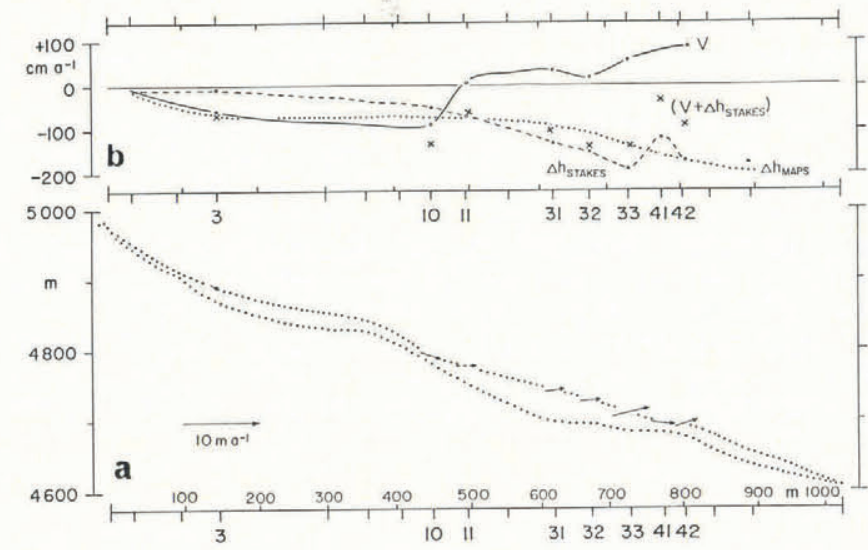

Fig. 4. Relation between vertical flow component, net balance, and surface lowering along the longitudinal axis of the glacier (dotted line in Figure 1). Horizontal scale in meters is counted from the highest point of the glacier down the longitudinal axis and station numbers are as in Figure 1.

a. Surface-flow velocity in longitudinal-vertical plane. Surface and bedrock topography are without vertical exaggeration. Velocity vectors in $\mathrm{ma}^{-1}$ are plotted at ten times the space scale in meters (i.e. $1 \mathrm{ma}^{-1}$ would be represented as a $10 \mathrm{~m}$ arrow). Arrows at stations 3,10 , 31,32 (old), 33 (old), and 42 refer to the 4 year interval 25-26 January 1982 to 1-2 January 1986. Arrow at station 11 belongs to the interval 21-23 December 1983 to 1-2 January 1986.

b. Variation of vertical flow component, height changes at stake network, and lowering of surface topography along the longitudinal axis, in $\mathrm{cm} \mathrm{a}^{-1}$. The vertical flow component $V$ is plotted here as positive upward from stations with information for the 4 year and 2 year periods described in Figure $4 a$, respectively. Height changes at stake network $\Delta h_{\mathrm{STAKES}}$ (broken line) refer to the budget year 1 March 1982 to 1 March 1986, with dots denoting the stations for which complete observations are available; otherwise the curve is plotted from the map in Figure 2. Observed time change of surface topography $\Delta h_{\text {MAPS }}$ (dotted line) is plotted for the interval March 1982 to March 1986, but a dot denotes station 11 for which values are for the 21-23 December 1983 to $1-2$ January 1986 interval (Fig. 4a). Crosses indicate the surface lowering $\left(V+\Delta h_{\text {STAKES }}\right)$ obtained from the vertical velocity (solid line) and the height change at the stake network (broken line). 
and the horizontal component of surface flow in the plane described by the central line is $u=\Delta s / \Delta t$.

The vertical and horizontal surface-flow components were calculated for the net-balance stakes located near the central line. For stakes 3, 10, 31, 32 (old), 33 (old), 42, and 41 , evaluation was possible for the 4 year period $25-28$ January 1982 to 1-2 January 1986. For stake 11, calculations were limited to the interval $21-23$ December 1983 to 1-2 January 1986.

The resultant surface-flow velocity in the longitudinalvertical plane is shown in Figure 4a. As described for the 1978-82 evaluations (Hastenrath, 1983), the flow vector is directed downward in the upper glacier, and upward in the lower glacier. This feature is enhanced in Figure $4 \mathrm{~b}$, designed to elucidate the relationship of net balance, ice flow, and surface lowering, or in fact the ice-mass continuity.

Ice-flow components were calculated from EDM measurements of stake coordinates and tape readings of net balance, for both of which error tolerances of a few centimeters were given in section 2. Accordingly, ice-flow components are determined here within a few $\mathrm{cm} \mathrm{a}^{-1}$.

\section{MASS CONTINUITY}

The map of the height change measured with respect to the stake network (Fig. 2) and the map of surfacetopography change (Fig. 3), both for the 1982-86 time span, are similar in their general magnitude and spatial patterns of change, in that both show largest values in the lower glacier. Differences between the two maps are to be expected not only because of the limited spatial resolution of the stake network, but also as a result of mass redistribution related to the flow dynamics (Hastenrath, 1983).

The difference between net-balance height changes (Fig. 2) and observed surface lowering (Fig. 3) varies with elevation, as is also borne out in the evaluation by $50 \mathrm{~m}$ elevation bands in Table I. The following features of Table

TABLE I. HEIGHT CHANGES DERIVED FROM MAPPING OF SURFACE TOPOGRAPHY $H_{\mathrm{m}}$, HEIGHT CHANGES OBTAINED FROM READINGS OF NET BALANCE STAKES $H_{\text {Sa }}$, AND LIQUID WATER-EQUIVALENT NET BALANCE $\triangle_{\text {SO }}$, IN CENTIMETERS AND FOR THE INTERVAL MARCH 1982-MARCH 1986, BY $50 \mathrm{~m}$ ELEVATION BANDS (OF 1982 MAPPING)

$\begin{array}{rrrr}\begin{array}{c}\text { Elevation } \\ \mathrm{m}\end{array} & \begin{array}{r}H_{\mathrm{m}} \\ \mathrm{cm}\end{array} & \begin{array}{c}H_{\mathrm{sa}} \\ \mathrm{cm}\end{array} & \begin{array}{c}\Delta_{\mathrm{sa}} \\ \mathrm{cm}\end{array} \\ 5000 & -407 & -67 & -40 \\ 4950 & -390 & -45 & -27 \\ 5900 & -343 & -147 & -88 \\ 4850 & -332 & -200 & -134 \\ 4800 & -425 & -391 & -313 \\ 4750 & -542 & -606 & -545 \\ 4700 & -692 & -800 & -720 \\ 4650 & -887 & -1052 & -947 \\ 4600 & -1000 & -1167 & -1050 \\ 4550 & & & \end{array}$

\section{Glacier}

average
I are noteworthy and in agreement with the evaluations for 1978-82. For the glacier as a whole, the two independent techniques yield thickness or volume decreases agreeing within $20 \%$, which is consistent with the tolerances in spatial sampling and in graphical evaluations. In the upper glacier, the height decrease derived from the consecutive mapping $\left(-H_{\mathrm{m}}\right)$ is larger than that obtained from the stake network $\left(-H_{\mathrm{sa}}\right)$, while the opposite is found in the lower glacier.

However, these contrasts between $H_{\mathrm{m}}$ and $H_{\mathrm{sa}}$ in both the upper and lower glacier are rather less for 1982-86 than for the 1978-82 interval. Table II summarizes evaluations of the quantity $\left(H_{\mathrm{m}}-H_{\mathrm{sa}}\right)$ for the upper and lower parts of the glacier separately for the two time intervals. Part A of Table II lists the values computed along the longitudinal glacier axis (Figs 1 and 4), while part B

TABLE II. COMPARISON OF THE EFFECT OF MASS REDISTRIBUTION BY ICE FLOW DURING THE 1978-82 INTERVAL VERSUS THE 1982-86 INTERVAL. LISTED IS THE QUANTITY $\left(H_{\mathrm{m}}-H_{\mathrm{sa}}\right)$ IN $\mathrm{cm} \mathrm{a}^{-1}$ IN THE UPPER $(>4800 \mathrm{~m})$ AND LOWER $(<4800 \mathrm{~m})$ PARTS OF THE GLACIER, WHERE $H_{\mathrm{m}}$ IS THE HEIGHT CHANGE DERIVED FROM SUCCESSIVE MAPPING OF SURFACE TOPOGRAPHY, AND $H_{\mathrm{Sa}}$ IS THE HEIGHT CHANGE OBTAINED FROM READINGS OF NET-BALANCE STAKES. PART A LISTS VALUES COMPUTED ALONG THE LONGITUDINAL GLACIER AXIS (FIGS 1 AND 4), WHILE VALUES IN PART B ARE OBTAINED FROM EVALUATIONS OVER THE ENTIRE AREA OF THE TWO HEIGHT DOMAINS (TABLE I), UPON ADJUSTMENT FOR ALL-GLACIER DISCREPANCIES BETWEEN $H_{\mathrm{m}}$ AND $H_{\mathrm{sa}}$

\section{$1978-82 \quad 1982-86$}

A. Along longitudinal axis (see Fig. 4)

$>4800 \mathrm{~m}$

$-59 \quad-36$

$<4800 \mathrm{~m}$

$+40$

B. By area (see Table I)

$>4800 \mathrm{~m} \quad-35 \quad-30$

$<4800 \mathrm{~m}$

$+30$

$+25$

presents assessments over the entire areas of the two altitude domains, accounting for the all-glacier discrepancies between $H_{\mathrm{m}}$ and $H_{\mathrm{sa}}$. The results in parts $\mathrm{A}$ and $\mathrm{B}$ are not expected to be identical, not only because of the tolerances of the graphical evaluations, but particularly because conditions along the longitudinal axis differ from the average over the elevation band. It is most relevant, however, that in both modes of evaluation, A and B, Table II bears out for the more recent interval 1982-86 smaller negative values in the upper glacier and smaller positive numbers in the lower glacier. The mass redistribution due to the flow dynamics seemingly mitigates the surface lowering from the negative net balance in the lower glacier, while it enhances the topography decrease in the upper glacier. This effect of the ice flow is apparent for both 1978-82 and 1982-86, but it is much weaker for the latter interval. This is consistent with the documented progressive decrease of ice velocity, detailed elsewhere (Hastenrath, 1987).

Figure $4 \mathrm{~b}$ substantiates the pertinent processes responsible for the apparent relationship between net balance, flow dynamics, and surface lowering, suggested by Figures 2 and 3 , and Table I. Consistent with the longitudinal-vertical cross-section in Figure 4a, Figure $4 b$ shows the vertical component of surface ice flow directed downward in the upper glacier, but upward in the lower glacier. Net balance over 1982-86 is negative at all elevations, with losses increasing toward the lower glacier. The sum of these two contributions, expressed as geometric distance, can be expected to approximate the change in surface topography over the 4 year interval 1982-86. As 
detailed before for the 1978-82 period (Hastenrath, 1983), the surface lowering calculated from vertical flow velocity and net balance somewhat exceeds the value documented by the successive topographic mapping for the upper glacier, while the reverse difference is found in the lower glacier (Fig. 4b). As suggested before (Hastenrath, 1983), these systematic departures may be due to the tendency for confluent flow in the upper glacier and for diffluence in the lower glacier, resulting from the configuration of the glacier bed.

These findings rest on the error tolerances for the pertinent quantities presented in Table II and Figure $4 \mathrm{~b}$. Regarding Table II, the estimates in section 2 lead to uncertainties of tens of $\mathrm{cm} \mathrm{a}^{-1}$ for both $H_{\mathrm{m}}$ and $H_{\mathrm{sa}}$. In Figure $4 \mathrm{~b}$, consider the quantity $\left(V+\Delta h_{\text {STAKES }}\right)$. Error tolerances of a few $\mathrm{cm} \mathrm{a}^{-1}$ are given for the first term in the bracket in section 3 and for the second term in section 2 , so that $\left(V+\Delta h_{\text {STAKES }}\right)$ is known to a few $\mathrm{cm} \mathrm{a}^{-1}$. The systematic variation in magnitude and sign of the quantities $\left(H_{\mathrm{m}}-H_{\mathrm{sa}}\right)$ and $\left(V+\Delta h_{\text {STAKES }}\right)$ from the upper glacier towards the lower glacier, as shown by Table II and Figure 4 , is thus well established, while the differences between the 1978-82 and 1982-86 intervals are marginal.

In synthesis, the evaluations for the 1982-86 time span confirm the general role of flow dynamics for the altitude differentiation of ice-surface lowering. Indications of differences against the preceding 4 year interval 1978-82 appear related to the progressive slow-down of ice flow entailing a reduction in the mass redistribution. Thus, the surface lowering becomes increasingly controlled by the in-situ net balance, rather than by the ice-flow dynamics of the glacier as a whole.

\section{CONCLUSIONS}

In March 1986, the second 4 year phase of a long-term observation program was completed on Lewis Glacier. Net-balance measurements at a network of stakes, together with repeated mapping of the ice-surface topography, again allowed assessment of the mass economy by both "glaciological" and "geodetic" methods. The general findings on the relation between net balance, ice flow, and surface lowering obtained in the first 4 year observation phase are confirmed. In addition, there are indications of long-term changes, which appear related to the progressive slow-down of ice flow reducing the mass redistribution within the glacier, so that the thinning of the glacier becomes increasingly controlled by the in-situ net balance. This simplifies the inference of the future behavior of Lewis Glacier, a topic to be pursued in a later paper.

\section{ACKNOWLEDGEMENTS}

This study was supported by U.S. National Science Foundation grant EAR83-17722 and National Geographic Society grant 1769-84. P. Kruss participated in the 1981-82 field work, and N. Bhatt, R.A. Caukwell, and W. Hime in the subsequent expeditions. I thank the anonymous reviewers for constructive comments. The research was authorized by the Office of the President, Republic of Kenya.

\section{REFERENCES}

Bhatt, N., and others. 1980. Ice thickness determination at Lewis Glacier, Mount Kenya: seismology, gravimetry, dynamics, by $\mathrm{N}$. Bhatt, S. Hastenrath, and P. Kruss. Zeitschrift für Gletscherkunde und Glazialgeologie, Bd. 16, Ht. 2, p. 213-28.

Caukwell, R.A., and Hastenrath, S. 1982. Variations of Lewis Glacier, Mount Kenya, 1978-82. Erdkunde, Bd. 36, Ht. 4, p. 299-303.

Hastenrath, S. 1983. Net balance, surface lowering, and ice flow pattern in the interior of Lewis Glacier, Mount Kenya, Kenya. Journal of Glaciology, Vol. 29, No. 103, p. 392-402.

Hastenrath, S. 1984. The glaciers of equatorial East Africa. Dordrecht, etc., D. Reidel Publishing Co.

Hastenrath, S. 1987. Continued decrease of ice-flow velocity at Lewis Glacier, Mount Kenya, East Africa. Journal of Glaciology, Vol. 33, No. 113, p. 79-82.

Hastenrath, S., and Caukwell, R.A. 1987. Variations of Lewis Glacier, Mount Kenya, 1982-86. Erdkunde, Bd. 41, Ht. 1, p. 37-41.

Hoinkes, H. 1970. Methoden und Möglichkeiten von Massenhaushaltsstudien auf Gletschern. Ergebnisse der Messreihe Hintereisferner (Ötztaler Alpen) 1953-1968. Zeitschrift für Gletscherkunde und Glazialgeologie, Bd. 6, p. 37-90. 